\title{
VALORES NORMAIS DA CONCENTRAÇÃO PROTÉICA DO LÍQÜIDO CEFALORRAQUIDIANO: VARIAÇÕES LIGADAS AO LOCAL DE COLHEITA DA AMOSTRA
}

\author{
A. Spina-França * \\ ISAAC AMAR **
}

Em estudo sôbre a determinação das proteinas do líqüido cefalorraquidiano (LCR), Frantzen ${ }^{2}$ salienta que ainda não se conhece método que reúna as condições para torná-lo o de escolha obrigatória. Essa razão explica a quantidade de métodos existentes, obrigando que cada laboratório selecione aquêle que pareça o mais satisfatório.

Comparando um método gravimétrico, dois colorimétricos e dois turbidimétricos, concluímos pela melhor viabilidade prática daquele padronizado por Bossak e col.1, também conhecido por método do Venereal Diseases Research Laboratory (V.D.R.L.). A conclusão se baseou, em especial, no fato de estar êste método sujeito apenas a pequena influência do êrro instrumental efetivo e das variações da relação entre albumina e globulinas. A simplicidade da técnica e a boa reprodutibilidade constituem outros fatôres que permitem recomendar seu emprêgo em laboratório clínico. Adotando êsse método é necessário estabelecer quais os valores normais e os limites das variações fisiológicas correspondentes à proteinorraquia total. Em relação aos últimos importa conhecer também as variações devidas ao local de colheita da amostra (ventricular, cisternal ou lombar), ao sexo, à idade e à raça. Em publicação anterior' 6 foram apresentados os resultados normais para o LCR colhido da cisterna magna (punção suboccipital), concluindo-se que a taxa de $30 \mathrm{mg}$ por $100 \mathrm{ml}$ representa o limite superior normal para o LCR colhido por essa via. As variações dependentes do local da colheita da amostra de LCR serão consideradas nesta publicação; ulteriormente serão estudadas aquelas ligadas ao sexo, à idade e à raça.

\section{MATERIAL E MÉTODOS}

Foi determinada a proteinorraquia total do LCR de 932 pacientes atendidos no Hospital das Clínicas: em 39 a amostra foi colhida por punção de um dos ventriculos laterais (punçāo ventricular); em 676, da cisterna magna (punção suboccipital); em 217, do fundo de saco lombar (punção lombar).

Trabalho da Clínica Neurológica (Prof. A. Tolosa) e da Seç̧ão de Liqüido Cefalorraquidiano do Laboratório Central (Dr. O. A. Germek) do Hospital das Clínicas da Fac. Med. da Univ, de São Paulo: * Assistente; ** Médico estagiário. 
Em todos os casos a pressão liquórica era normal e as amostras se caracterizavam por número de células normal, negatividade das reações para pesquisa de globulinas (de Pandy e Nonne), negatividade da reação coloidal de Takata-Ara e negatividade das reações de fixação do complemento para sífilis e para cisticercose.

O método empregado para a determinação foi o do V.D.R.L. ${ }^{1}{ }^{3}$, cuja técnica é a seguinte: $a$ ) em tubo de ensaio juntar a $1 \mathrm{ml}$ de LCR, $1 \mathrm{ml}$ de ácido tricloracético a 10\%; misturar por inversão, sem formar bôlhas e colocar em banho-maria a $37^{\circ} \mathrm{C}$ por 10 minutos; inverter novamente e proceder à leitura; $b$ ) leitura em espectrofotômetro Coleman $\mathrm{Jr}$. modêlo $6-\mathrm{A}$, cubas 6-308, comprimento de onda de 420 milimicra; usar como blanque uma mistura de $1 \mathrm{ml}$ de solução fisiológica e $1 \mathrm{ml}$ de ácido tricloracético a $10 \%$, submetida aos mesmos procedimentos citados para a amostra de LCR em estudo; c) transformar a percentagem de transmissão encontrada no valor correspondente de proteinorraquia total por meio de tabela de conversão estabelecida prèviamente.

A tabela de conversāo é estabelecida em relação à densidade óptica obtida para soluçōes cuja concentração protéica seja conhecida (sôro sangüineo ou LCR, de preferência); o método de Kjeldahl pode ser utilizado para a determinação da concentração protéica total das soluções usadas para a calibração do método. Para o colorímetro utilizado a relação ențre a concentração protéica e a percentagem de transmissão obedece à equação da reta dentro dos limites de transmissão de 30 a $90 \%$. Qualquer colorímetro pode ser utilizado desde que o método seja adaptado. Para isso, manter como pontos fundamentais o emprêgo de partes iguais de LCR e de ácido tricloracético a $10 \%$ e o emprêgo de comprimento de onda luminosa na região de 420 milimicra.

\section{RESULTADOS}

As amostras estudadas se acham reunidas no quadro 1, segundo a proteinorraquia total encontrada e distribuidas conforme o local da colheita.

A média, o desvio padrão e o desvio da média obtidos pela análise estatística das concentrações protéicas encontradas para as amostras de LCR ventricular, da cisterna magna e lombar estão reunidas no quadro 2.

Para comparar as diferenças entre a concentração protéica das amostras de LCR ventricular, da cisterna magna e lombar foi empregado o teste de $t$. Em relação às estimativas da proteinorraquia das amostras colhidas da cisterna magna, os teores encontrados no LCR ventricular apresentam diferença significativa $(t=$ $=2,59)$. Para a proteinorraquia das amostras colhidas da cisterna magna $\mathbf{e}$ da região lombar, a diferença é altamente significativa $(t=14,89)$.

\section{COMENTARIOS}

É sabido que a concentração protéica do LCR varia conforme o local do sistema liquórico de onde a amostra foi colhida. A concentração protéica nas amostras ventriculares é menor que aquela encontrada no LCR lombar, ocupando posição intermediária à das amostras provenientes da cisterna magna. Esta variação fisiológica é conhecida mas sua expressão numérica depende do método de determinação da proteinorraquia total utilizado. Empregando o método do V.D.R.L., essas variações fisiológicas são representadas pelas estimativas do quadro 2 . 


\begin{tabular}{|c|c|c|c|}
\hline \multirow{2}{*}{ Proteinorraquia $(\mathrm{mg} / 100 \mathrm{mI})$} & \multicolumn{3}{|c|}{ Freqüência } \\
\hline & V & so & $L$ \\
\hline 4 & 1 & & \\
\hline 5 & & 1 & \\
\hline 6 & & 2 & \\
\hline 7 & & 7 & \\
\hline 8 & 4 & 9 & \\
\hline 9 & 1 & 13 & \\
\hline 10 & 2 & 20 & 3 \\
\hline 11 & 3 & 16 & \\
\hline 12 & 4 & 54 & 4 \\
\hline 13 & 2 & 52 & 2 \\
\hline 14 & 1 & 50 & 3 \\
\hline 15 & 4 & 42 & 7 \\
\hline 16 & 2 & 58 & 7 \\
\hline 17 & 1 & 55 & 10 \\
\hline 18 & 2 & 46 & 11 \\
\hline 19 & 4 & 63 & 18 \\
\hline 20 & 2 & 34 & 12 \\
\hline 21 & 2 & 40 & 8 \\
\hline 22 & 1 & 18 & 10 \\
\hline 23 & 2 & 30 & 19 \\
\hline 24 & 1 & 13 & 13 \\
\hline 25 & & 13 & 11 \\
\hline 26 & & 13 & 9 \\
\hline 27 & & 14 & 8 \\
\hline 28 & & 6 & 11 \\
\hline 29 & & 2 & 11 \\
\hline 30 & & 3 & 5 \\
\hline 31 & & 2 & 3 \\
\hline 32 & & & 4 \\
\hline 33 & & & 3 \\
\hline 34 & & & 5 \\
\hline 35 & & & 9 \\
\hline 36 & & & 5 \\
\hline 37 & & & 1 \\
\hline 38 & & & \\
\hline 39 & & & 1 \\
\hline 40 & & & 1 \\
\hline 41 & & & 2 \\
\hline 42 & & & \\
\hline 43 & & & 1 \\
\hline
\end{tabular}

Quadro 1 - Distribuição, segundo a freqüência, da proteinorraquia total para as amostras analisadas: ventriculares $(V)$, da cisterna magna (SO) e lombares $(L)$. 


\begin{tabular}{|c|c|c|c|}
\hline Estimativas & $V$ & so & $L$ \\
\hline Número de amostras & 39 & 676 & 217 \\
\hline Média $\ldots \ldots \ldots \ldots \ldots \ldots \ldots$ & 14,9 & 17,0 & 24,0 \\
\hline Desvio padrão $\ldots \ldots \ldots \ldots \ldots \ldots \ldots$ & 5,0 & 4,8 & 6,3 \\
\hline Desvio da média ... & 0,81 & 0,18 & 0,43 \\
\hline
\end{tabular}

Quadro 2 - Estimativas referentes à proteinorraquia total das amostras de LCR estudadas (V, ventriculares; SO, da cisterna magna; L, lombares).

\begin{tabular}{ccc}
\hline LCR & Minimo & Máximo \\
\hline V. & 5 & 25 \\
S.O. & 5 & 30 \\
L. & 8 & 40 \\
\hline
\end{tabular}

Quadro 3 - Limites para as variacões fisiológicas da concentração protéica total do LCR ventricular (V.), da cisterna magna (S.O.) e lombar (L.).

O maior número de determinações da proteinorraquia total do LCR colhido da cisterna magna relatado nesta série é devido à maior freqüência do emprêgo da punção suboccipital para a colheita do LCR em nosso meio. Este número maior de amostras estudado dá às estimativas achadas para o LCR cisternal maior precisão, motivo pelo qual foram tomadas como base para interpretar as estimativas achadas para as amostras de LCR ventricular e lombar. Esses valores são representados pela média de $17 \mathrm{mg}$ por $100 \mathrm{ml}$; para os limites inferior e superior das variações fisiológicas podem ser tomados os limites fiduciais correspondentes a $t=1 \%$, respectivamente, 4,6 e $29,4 \mathrm{mg}$ por $100 \mathrm{ml}$.

A proteinorraquia total do LCR lombar é representada em média pela taxa de $24 \mathrm{mg}$ por $100 \mathrm{ml}$ e os limites inferior e superior das variações fisiológicas por 7,6 e 40,4 mg por $100 \mathrm{ml}$, considerando também os limites fiduciais correspondentes a $t=1 \%$.

A pequena freqüência com que a via ventricular é utilizada para a colheita do LCR explica o pequeno número de amostras ventriculares desta série. Embora fôssem inteiramente normais quanto ao restante do exame, provinham quase sempre de pacientes com alterações do sistema de intercomunicação ventrículo-subaracnóidea (hidrocefalia interna, hipertensão intracraniana) e, em vista disso, torna-se difícil, como salienta Lange ${ }^{4}$, julgar 
sôbre se representam realmente os valores normais para o LCR ventricular. Em vista de os valores citados na literatura para a concentração protéica normal do LCR ventricular serem baseados na análise de amostras colhidas de pacientes com afecções do mesmo tipo que nesta série, as concentrações achadas são utilizadas para representar tais valores em relação ao método do V.D.R.L. O desvio da média é maior neste grupo de amostras, em virtude das grandes variações observadas entre as taxas; apesar disso, o quadro 1 permite verificar que as amostras ventriculares se distribuem, em relação à taxa protéica total, em niveis inferiores aos das amostras cisternais e lombares. De fato, êsses valores são representados pela média de $14,9 \mathrm{mg}$ por $100 \mathrm{ml}$, menor que aquelas achadas para as amostras cisternais e lombares e a diferença existente é significativa do ponto de vista estatístico. Para limites mínimo e máximo, entretanto, os limites fiduciais adotados correspondem a $t=5 \%$, em vista do pequeno número de amostras estudado. As taxas de 4,8 e $25,0 \mathrm{mg}$, respectivamente, figuram tais limites.

Do ponto de vista prático os valores do quadro 3 representam os limites fisiológicos das variações da proteinorraquia total do LCR ventricular, cisternal e lombar, quando o método do V.D.R.L. é empregado e segundo a análise estatística do material apresentado.

Os resultados apresentados confirmam aquêles obtidos por outros métodos, mostrando que a proteinorraquia total costuma ser maior no LCR lombar e menor no ventricular, sendo representada por valores intermediários a do LCR colhido da cisterna magna (punção suboccipital). As diferenças entre as médias dêste último grupo de amostras e os grupos anteriores, é maior em relação às amostras de LCR lombar que as de LCR ventricular.

\section{RESUMO}

Pelo emprêgo do método do V.D.R.L. foram estudadas as variações fisiológicas da proteinorraquia total ligadas ao local de onde as amostras foram colhidas. Pela análise dos resultados referentes a 932 amostras de LCR foram calculados os limites de tais variações, resumidos no quadro 3 .

\section{SUMMARY}

Cerebrospinal fluid total protein content: changes related to the site of collection of the sample.

In order to study the physiological changes of total protein content related to the site of its collection, 932 cerebrospinal fluid samples were analysed by V.D.R.L.'s trichloracetic acid method.

Statistical analysis of the results showed that the total concentration of protein in ventricular samples is lower than that in lumbar ones; the total protein content of samples collected from the cisterna magna (suboccipital puncture) are represented by intermediate values. 
Such data confirm the results registered in the literature, where other methods of protein determination are used and establish the limits of normal changes in relation to the V.D.R.L.'s method.

The mean values and its deviations are shown in table 2; the limits representing the normal changes in respect to the site of collection are presented in table 3 .

\section{REFERENCIAS}

1. BOSSAK, H. N.; ROSENBERG, A. A.; HARRIS, A. - A quantitative turbidimetric method for the determination of spinal fluid protein. $J$. Ven. Dis. Inform., 30:100-103 (abril) 1949. 2. FRANTZEN, E. - A survey of methods for the determination of the protein fractions in the cerebrospinal fluid. Acta Psychiat. et Neurol. Scandinavica, 30:217-225 (março) 1955. 3. HARDING, V. L.; HARRIS, A. - The effect of temperature variants on quantitative turbidimetric determinations of spinal fluid protein, using trichloracetic acid. J. Ven. Dis. Inform., 30:325-327 (novembro) 1949. 4. LANGE, O. - Proteínas do líqüido cefalorraquidiano: métodos para sua determinação; valor para o diagnóstico e prognóstico de algumas afecções do sistema nervoso central. Rev. Assoc. Paulista de Med., 4:153-169 (abril) 1934. 5. SPINA-FRANCA, A.; CERQUEIRA, F. M. C.; AMAR, I. - Proteinorraquia: estudo crítico de métodos de dosagem. Arq. Neuro-Psiquiat., 13:303-312 (dezembro) 1955. 6. SPINA-FRANÇA, A.; AMAR, I. - Valores normais da concentração protéica do liqüidọo cefalorraquidiano cisternal. Arq. Neuro-Psiquiat., 15:27-34 (março) 1957.

Clinica Neurológica - Hospital das Clinicas da Fac. Med. da Univ. de São Paulo - Caixa Postal 3461 - São Paulo, Brasil. 